\title{
Telemedicine and eHealth in Poland from 1995 to 2015
}

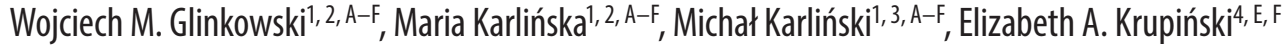 \\ ${ }^{1}$ Polish Telemedicine and eHealth Society, Warszawa, Poland \\ 2 Department of Medical Informatics and Telemedicine, Medical University of Warsaw, Poland \\ ${ }^{3} 2^{\text {nd }}$ Department of Neurology, Institute of Psychiatry and Neurology, Warszawa, Poland \\ ${ }^{4}$ Department of Radiology, Emory University School of Medicine, Atlanta, United States \\ A - research concept and design; B - collection and/or assembly of data; $\mathrm{C}$ - data analysis and interpretation; \\ $D$ - writing the article; $E$ - critical revision of the article; $F$ - final approval of the article
}

\section{Address for correspondence \\ Wojciech M. Glinkowski}

E-mail:w.glinkowski@gmail.com

\section{Funding sources}

None declared

\section{Conflict of interest}

None declared

Received on December 7, 2016

Reviewed on April 7, 2017

Accepted on May 26, 2017

\begin{abstract}
The aim of this study is to present a review based on the literature and proceedings from selected telemedicine conferences. The review was developed using the PRISMA framework. The Embase and PubMed (updated until July 13, 2015) literature databases were searched for telemedicine-related terms and Poland. The literature search identified 129 eligible articles in the databases and 85 in conference proceedings until July 2015. Articles measured as a number of contributions per year presented a similar rising, fluctuating and almost parallel pattern. Fifty-nine percent of the reviewed papers were published in impacted journals. Almost half of all publications presented original papers. The published articles concerned mostly cardiology (16\%), family medicine (15\%) and pathology (11\%). Conference proceedings papers concerned orthopedics (29\%, significantly more frequent; $p<0.001)$ and cardiology (14\%). Scientific activity of researchers and practitioners in Poland in the field of telemedicine is not high, but it is increasing over time. There is a tendency to present the research rather in high-quality journals instead of conferences before publication. The occurrence of individual medical specialty telemedicine in Poland may reflect country-specific needs.
\end{abstract}

Key words: Poland, telemedicine, literature review, telehealth, eHealth

DOI

10.17219/acem/74124

\section{Copyright}

Copyright by Author(s)

This is an article distributed under the terms of the

Creative Commons Attribution Non-Commercial License

(http://creativecommons.org/licenses/by-nc-nd/4.0/) 


\section{Introduction}

Over the last 2 decades, substantial development has been observed in telemedicine, including eHealth, mHealth and other related terms often used to describe the delivery of healthcare at a distance using a variety of telecommunication devices and systems. The terms "telemedicine" and "eHealth" are often used interchangeably, but their semantic meanings are not identical. According to the American Telemedicine Association, the term "telemedicine" means "the use of medical information exchanged from one site to another via electronic communications to improve a patient's clinical health status, including applications and services using two-way video, email, smartphones, wireless tools, and other forms of telecommunications technology." ${ }^{1}$ The Polish Telemedicine and eHealth Society considers telemedicine to cover the entire spectrum of medical services, including liability and licensing. ${ }^{2}$ Thus, eHealth is a broader term that also includes several aspects of medi$\mathrm{cal} /$ health or clinical information systems. The idea of performing medical procedures at a distance and/or using communications technology has a long tradition in Poland. The first example found in the literature documented the implementation of telemedicine in Lviv (currently Ukraine) in 1935. Professors Marian Franke and Witold Lipiński organized the first clinical teleelectrocardiography (tele-ECG) system, which allowed wired transmission at a distance of approx. $500 \mathrm{~m} .^{3}$ The next documented Polish application of telemedicine occurred 60 years later. As a Central European country with a population of 38.5 million, Poland and its pattern of telemedicine development may be representative of the whole Central and Eastern European region.

Studies support the contention that telemedicine is at least as good as conventional services regarding effectiveness, cost and patient outcomes. ${ }^{4}$ The successful integration of telemedicine into existing healthcare enterprises has been a challenge for both users and researchers, as it often tends to focus on organizational issues, neglecting the social framework and human factors. Telemedicine has become an important element of healthcare systems, particularly in western societies. Scientific publications and conference proceedings are often used to gauge the level of interest in and the implementation of new paradigms of telehealthcare. There has been no or little assessment of telemedicine research productivity and efficiency in Poland to date. The aim of this study was to review the literature systematically addressing telemedicine and eHealth in Poland, to provide a general overview of the current status and time trends in this area of research. The expected potential value of this type of review is to help find country-specific implementations and promote further research efforts not only in Poland, but also in other countries from the region.

\section{Material and methods}

A systematic review of the literature was chosen as an appropriate method to study the development of telemedicine and eHealth implementations in Poland. The study followed the PRISMA statement for reporting systematic reviews and meta-analyses of studies that evaluate healthcare interventions. ${ }^{5}$ Investigators experienced in telemedicine research independently searched PubMed and Embase for all reports on telemedicine in Poland. Search terms were formulated using $\mathrm{MeSH}$ headings and included the following combination: "eHealth" OR "telemedicine" OR "mobile health" OR "mHealth" OR "telehealth" OR "remote consultation") AND ("Poland" OR "Polish"). After the screening of titles and abstracts of all initially identified publications, duplicates were removed and the full texts of the remaining articles were obtained for further analysis. There were no language or date restrictions, and the search was last updated on July 13, 2015.

The inclusion criteria were fulfilled if publications: 1) clearly addressed the issue of telemedicine in Poland; 2) reported original findings or reviewed the literature; and 3) were published in a peer-reviewed journal.

The authors carried out a secondary literature search to identify all presentation reports and abstracts by Polish authors for the Med-e-Tel and Medicine 2.0 conferences. Med-e-Tel is the official conference of the International Society for Telemedicine and eHealth held annually since 2000. Medicine 2.0 is a world conference on social media, mobile applications and the Internet in health, medicine and biomedical research, held annually since 2008. Although there are other telemedicine meetings, Med$\mathrm{e}-\mathrm{Tel}$ is the main European telemedicine meeting Polish researchers are likely to attend. The search covered electronic proceedings through July 2015. After screening the abstracts, all of the full-text papers were reviewed by 2 investigators (MK and MK). Both reviewers had to agree on whether the paper met the inclusion criteria to include the paper in the final analysis. Disagreements were resolved by discussion with the $3^{\text {rd }}$ investigator (WG).

A predefined form was used to extract the following information from the articles: 1) year of publication; 2) list of authors and their affiliations; 3 ) details of the publishing journal; 4) area of medicine; 5) telemedical technology; 6) type of publication, i.e., controlled study, observational or feasibility study, survey, description of functionality, review, or other non-original paper; and 7) main results. The data was extracted and checked for validity. The impact factor (IF) of each journal was obtained from Journal Citation Reports. The identified studies were very heterogeneous regarding scope and methodology, which allowed for only semi-quantitative statistics. Categorical variables are presented as the number of observations with the ratio. Due to a non-normal distribution, continuous variables are presented as the median with range. Proportions of articles and conference proceedings addressing identical 
areas of telemedicine were compared using the two-tailed Fisher's exact test. Calculations were carried out using the STATISTICA v. 10.0 software package (Stat Soft Inc., Tulsa, USA). Probability values $<0.05$ were considered statistically significant.

\section{Results}

Out of the 632 records retrieved from the initial database search, 109 were eligible for the final review, and an additional 20 articles were identified through reference search. Only selected papers are cited here, but all of them were thoroughly read and analyzed. The details of the screening process are presented in Fig. 1.

The peer-review status of the first published paper by Franke and Lipiński remains unknown. ${ }^{3}$ The peer-review process is obvious for the paper addressing telemedicine in Poland published in $1995 .{ }^{6}$ The number of articles published per year fluctuated from 0 to 16, with an overall increasing trend (Fig. 2).

The descriptive statistics of the excerpts from the articles and their classifications are presented in Table 1.

Telemedicine and eHealth were mostly utilized only in selected clinical disciplines like cardiology (16\%), family medicine (15\%) and pathology (11\%), probably due to the clinical needs, research interest or other facilitated use (Fig. 3). However, no further investigation was conducted following that observation due to the review protocol.

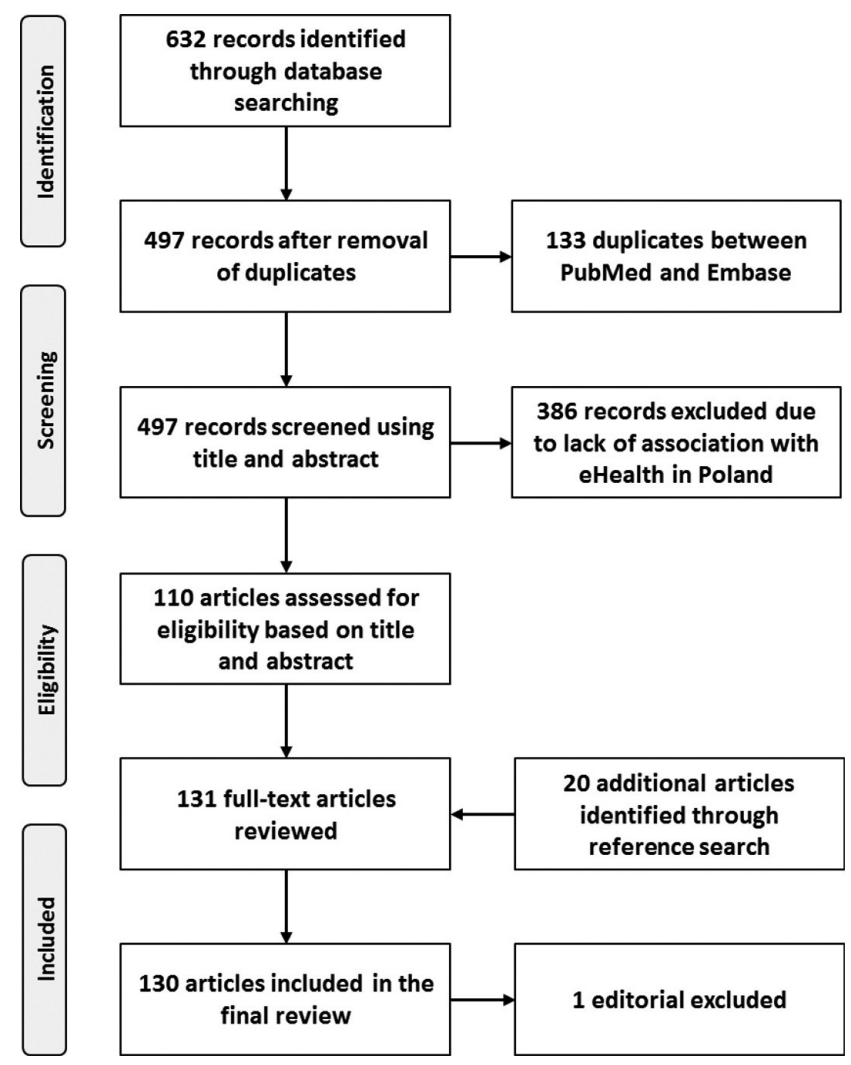

Fig. 1. PRISMA flowchart showing the selection process of eligible articles
Table 1. Summary characteristics of the reviewed articles $(n=129)$

\begin{tabular}{|l|c|}
\multicolumn{1}{|c|}{ Published articles } & $\mathrm{n}(\%)$ \\
\hline Authors & $17(13.2)$ \\
international collaboration & $3(1-22)$ \\
number of authors, median (range) & $54(41.9)$ \\
$1-2$ authors & $37(28.7)$ \\
$\geq 5$ authors & \\
Journal characteristics & $79(61.2)$ \\
non-Polish journal & $77(58.9)$ \\
impact factor $>0.00$ & $1.48(0.26-7.08)$ \\
impact factor (if applicable), median (range) & \\
\hline Language & $91(70.5)$ \\
full text in English & $38(24.0)$ \\
at least abstract in English & $7(5.4)$ \\
only in Polish & \\
\hline Type of publication* & $19(14.7)$ \\
controlled studies & $31(24.0)$ \\
observational or feasibility studies & $18(14.0)$ \\
surveys & $17(13.2)$ \\
descriptions of functionality & $51(39.5)$ \\
reviews and other non-original papers &
\end{tabular}

* Publication may have had mixed methodology, therefore the denominator is 136 .

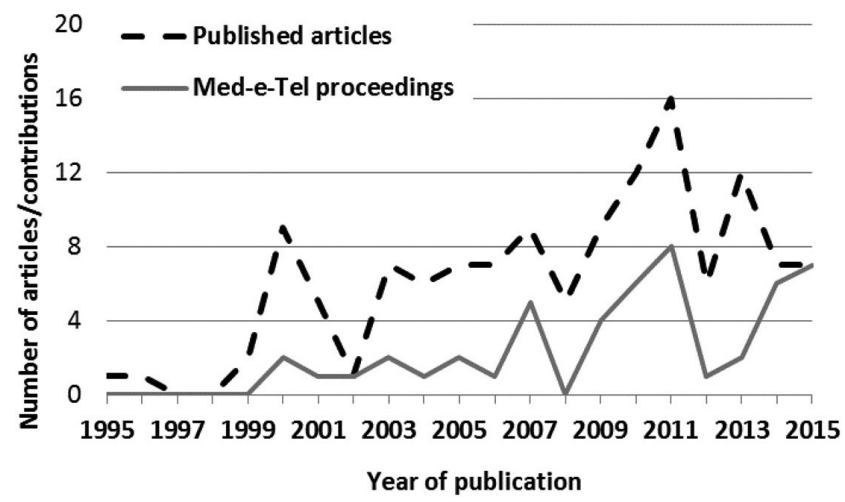

Fig. 2. Annual volume of publications and Med-e-Tel proceedings from Polish authors

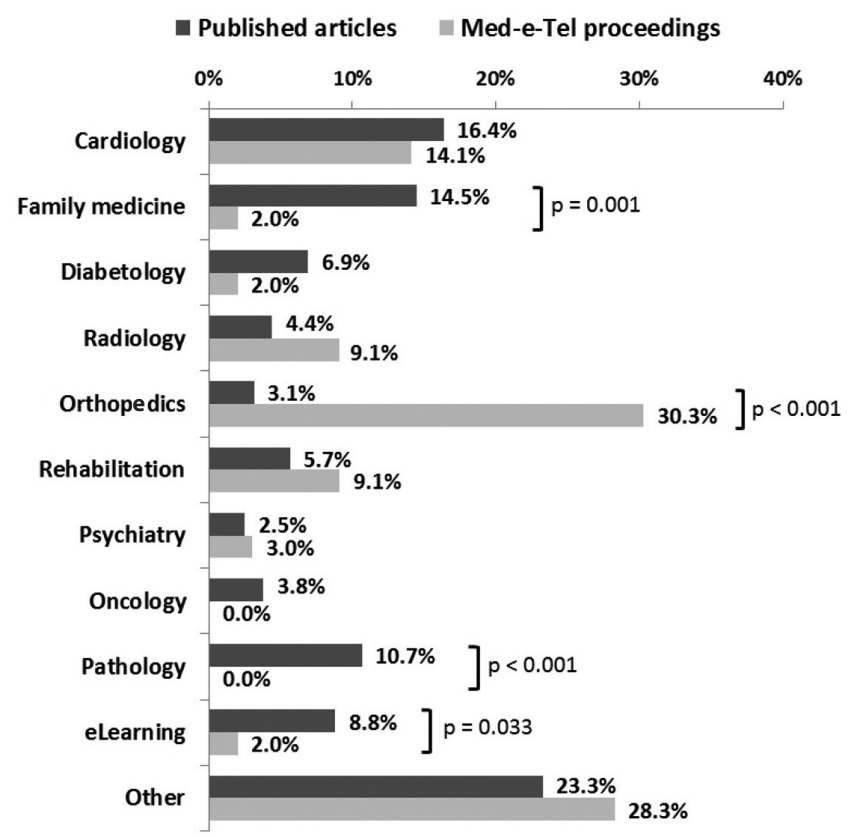

Fig. 3. Telemedicine application areas in reviewed articles and proceedings 
The search for conference materials revealed 82 articles (Med-e-Tel - 82 papers and Medicine 2.0 - only 3 papers) that were relevant for a full review. Polish authors have contributed to the conferences since the first Med-e-Tel meeting in 2000, with a visible, increasing trend over the years (Fig. 2). All but 2 contributions were original (not presented elsewhere). The most frequently addressed areas of telemedicine were orthopedics (29\%, significantly more frequent than in published papers; $\mathrm{p}<0.001$ ) and cardiology (14\%). Other medical disciplines were significantly less often presented during telemedicine-oriented conferences (particularly pathology and family medicine) than in published papers (Fig. 3).

\section{Discussion}

The analysis of publications addressing telemedicine on a national scale systematically is rather rare in the literature, possibly because authors have more of an institutional rather than countrywide perspective. The review of country-specific peer-reviewed publications and proceedings papers provides the opportunity to find common and diverse aspects of regional (countrywide) developments in the field.

Our analysis revealed that video conferences and imaging data transmission via satellite between Polish and German clinicians from departments of radiology in Berlin and Wrocław opened the new age of telemedicine implementations in Poland in $1995 .{ }^{6}$ Since then, the Internet and other telecommunications-based systems have become important sources of health-related information that have started to supplement conventional health services across Europe. ${ }^{7,8}$ Research conducted in Poland and other countries clearly shows that the interest in telemedicine is growing. ${ }^{2}$ The acceptance of telemedicine and eHealth solutions is increasing in the general population and even undergraduate medical professionals. ${ }^{2,9,10}$

This review did not explicitly distinguish between telemedicine and eHealth applications in order to capture the broadest picture of research in this area in Poland to date. The current review reveals a few interesting trends. Despite differences in the total annual number of papers, Polish publications and conference proceedings seem to follow a similar (almost parallel) fluctuating pattern. Both curves in Fig. 2 show peaks in 2000, 2007 and 2011, and lows in 2008 and 2012. It would be interesting to know the reason for these peaks and valleys. It is possible that these cyclic patterns might be related to the funding of telemedicine projects. However, funding information was not always provided in the searched publications.

In general, published articles were expert opinions on telemedicine, with most focused on cardiology, family medicine, and pathology. ${ }^{11-24}$ Telecardiology seems to be a very prominent telemedicine sector in Poland, and cardiac telerehabilitation has become well-recognized due to several projects. ${ }^{14,20,25-27}$ Specialists in family medicine, primary care and internal medicine usually implement home telemonitoring of chronic diseases and blood pressure monitoring in their studies, and there are a few research groups focused on telediabetology. ${ }^{28,29}$ Telepathology was introduced in the 1990s in Poznan with the description of remote automatic microscope functionality, and several more papers focused on additional telepathology applications. ${ }^{23,24,30-32}$

We observed a significant impact of research focusing on otorhinolaryngology ("ear, nose and throat" or ENT), especially with using telemedicine for cochlear implant fitting. ${ }^{33,34}$ Teledermatology was not frequently mentioned in Polish studies. ${ }^{35}$ Telemedicine and eHealth implementations in psychology, psychiatry and neurology most frequently regarded psychotherapy techniques. ${ }^{36-40}$ The daily use of teleradiology to deal with the shortage of radiologists is rarely the topic of research - it is so well integrated into medical services that it is generally no longer regarded as innovative or challenging. ${ }^{25,41}$ Telepulmonology papers show mostly mature implementations. ${ }^{15,42}$ Papers in teleoncology are unique. ${ }^{43}$ Telemedicine use in orthopedics is well delineated and focuses on certain pathologies. ${ }^{44-46}$ The knowledge and attitude of nursing students toward telenursing were surveyed. ${ }^{47}$ Internet-based medical information use is represented well in several medical specialties. ${ }^{7,8,48,49}$

Other papers describe various telemedicine and eHealth technologies used in real or virtual patient care, and some even address the outdated but still operational use of the phone for teleconsultations. ${ }^{11,50-52}$ Papers on distance learning have been presented since 1995, initially as live broadcasts over satellite, then moving to Internet-based applications. ${ }^{6}$ Later studies have addressed many more aspects of e-learning, including barriers, virtual environments and the use of resources, such as virtual patient modules and grid medical libraries. ${ }^{14,53,54}$

It is not possible to directly relate the trends observed in Poland to what has been happening in other countries. ${ }^{55-57}$ Based on the almost constant increase in the global number of similar publications indexed in PubMed (from 366 papers indexed in the year 1995 to 2946 papers indexed in the year 2015), the contribution of the activity of Polish authors may be considered lower than expected for a country of this size and population. The current review may help other researchers with similar telecommunication and healthcare infrastructures.

This paper has limitations in that it used only 2 databases for the search, and used a limited set of telemedicineassociated terms, which may have influenced the number of retrieved articles. An additional limitation was the selection of only 2 conference proceedings, Med-e-Tel and Medicine 2.0, to include. An extended and methodologically improved review would likely enable a more detailed analysis of the telemedicine and eHealth status in Poland, and provide stronger conclusions. 


\section{Conclusions}

The scientific activity in the field of eHealth and telemedicine implementations in Poland did not achieve the level anticipated, given the growing use of telemedicine across Europe. However, it has increased over time. On the positive side, this search revealed that about half of the identified articles reported original contributions and more than a half were published in journals indexed in the Journal Citation Report. The relatively low number of controlled clinical studies (about 15\%) represents the underexploited scientific potential in this field. The profile of disciplines represented on the selected conferences seems to be skewed toward some specialties, which may reflect the fact that they are attended only by certain groups of researchers. This type of country-specific literature review may be helpful in assessing the state-of-the-art in research for a particular country, but may also serve as an example for other countries wanting to evaluate their research activities or to establish collaboration. Understanding the research and implementation activities within a given country may also help researchers, policy makers and healthcare officials to support and promote the use of telemedicine in their country.

\section{References}

1. Bajwa M. Emerging $21^{\text {st }}$ century medical technologies. Pak J Med Sci. 2014;30(3):649-655.

2. Glinkowski W, ed. Advances in international telemedicine and eHealth. Around the world. Warszawa: Medipage Ltd.; 2006.

3. Franke M, Lipiński W. Zmiany elektrograficzne w chorobach zakaźnych. Polska Gazeta Lekarska. 1936;15(9):1-11.

4. Hersh WR, Hickam DH, Severance SM, Dana TL, Krages KP, Helfand M. Telemedicine for the medicare population: Update. Evidence report/ technology assessment. 2006;(131):1-41.

5. Moher D, Liberati A, Tetzlaff J, Altman DG, Group P. Preferred reporting items for systematic reviews and meta-analyses: The PRISMA Statement. Open Med. 2009;3(3):e123-130.

6. Ricke J, Kleinholz L, Hosten N, et al. Telemedicine in rural areas. Experience with medical desktop-conferencing via satellite. J Telemed Telecare. 1995;1(4):224-228.

7. Andreassen HK, Bujnowska-Fedak MM, Chronaki CE, et al. European citizens' use of E-health services: A study of seven countries. BMC Public Health. 2007;7:53. doi:10.1186/1471-2458-7-53

8. Kummervold $\mathrm{PE}$, Chronaki $\mathrm{CE}$, Lausen $\mathrm{B}$, et al. eHealth trends in Europe 2005-2007: A population-based survey. J Med Internet Res. 2008;10(4):e42. doi:10.2196/jmir.1023

9. Glinkowski W, Ciszek B. WWW-based e-teaching of normal anatomy as an introduction to telemedicine and e-health. Telemed J E Health. 2007;13(5):535-544.

10. Glinkowski W, Pawłowska K, Kozłowska L. Telehealth and telenursing perception and knowledge among university students of nursing in Poland. Telemed J E Health. 2013;19(7):523-529. doi:10.1089/ tmj.2012.0217

11. Wysocki WM, Moesta KT, Schlag PM. Surgery, surgical education and surgical diagnostic procedures in the digital era. Med Sci Monit. 2003;9(3):RA69-75.

12. Duplaga M, Leszczuk M, Zielinski K. Improving access of associated states to advanced concepts in medical telematics - A day before the accession to EU. Int J Med Inform. 2006;75(3-4):300-305. doi:10.1016/j. ijmedinf.2005.08.014

13. Duplaga M. E-health development policies in new member states in Central Europe. World Hosp Health Serv. 2007;43(2):34-38.

14. Maciejewski M, Surtel W, Wojcik W, Masiak J, Dzida G, Horoch A.
Telemedical systems for home monitoring of patients with chronic conditions in rural environment. Ann Agric Environ Med. 2014;21(1): 167-173.

15. Duplaga M. The acceptance of e-health solutions among patients with chronic respiratory conditions. Telemed J E Health. 2013;19(9):683691. doi:10.1089/tmj.2012.0306

16. Grabowski M, Filipiak KJ, Rudowski R, Opolski G. Project of an expert system supporting risk stratification and therapeutic decision making in acute coronary syndromes. Pol J Pathol. 2003;54(3):205-208.

17. Sierdzinski J, Karpinski G. Electronic patient record and archive of records in Cardio.net system for telecardiology. Pol J Pathol. 2003;54(3):223-226.

18. Piotrowicz E. How to do: Telerehabilitation in heart failure patients. Cardiol J. 2012;19(3):243-248.

19. Piotrowicz E, Jasionowska A, Banaszak-Bednarczyk M, Gwilkowska J, Piotrowicz R. ECG telemonitoring during home-based cardiac rehabilitation in heart failure patients. J Telemed Telecare. 2012;18(4):193197. doi:10.1258/jtt.2012.111005

20. Piotrowicz E, Stepnowska M, Leszczynska-Iwanicka K, et al. Quality of life in heart failure patients undergoing home-based telerehabilitation versus outpatient rehabilitation: A randomized controlled study. Eur J Cardiovasc Nurs. 2015;14(3):256-263. doi:10.1177/1474515114537023

21. Bujnowska-Fedak MM, Staniszewski A, Steciwko A, Puchała E. System of telemedicine services designed for family doctors' practices. Telemed J E Health. 2000;6(4):449-452.

22. Bujnowska-Fedak MM, Puchala E, Steciwko A. Telemedicine for diabetes support in family doctors' practices: A pilot project. J Telemed Telecare. 2006;12(Suppl 1):8-10. doi:10.1258/135763306777978551

23. Szymas J, Lundin M. Five years of experience teaching pathology to dental students using the WebMicroscope. Diag Pathol. 2011;6(Suppl 1):S13. doi:10.1186/1746-1596-6-S1-S13

24. Slodkowska J, Markiewicz T, Grala B, et al. Accuracy of a remote quantitative image analysis in the whole slide images. Diagn Pathol. 2011;6(Suppl 1):S20. doi:10.1186/1746-1596-6-S1-S20

25. Gackowski A, Czekierda L, Chrustowicz A, et al. Development, implementation, and multicenter clinical validation of the TeleDICOM - Advanced, interactive teleconsultation system. J Digit Imaging. 2011;24(3):541-551. doi:10.1007/s10278-010-9303-8

26. Przybylski A, Zakrzewska-Koperska J, Maciag A, et al. Technical and practical aspects of remote monitoring of implantable cardioverter-defibrillator patients in Poland: Preliminary results. Kardiol Pol. 2009;67(5):505-511.

27. Piotrowicz E, Korzeniowska-Kubacka I, Chrapowicka A, et al. Feasibility of home-based cardiac telerehabilitation: Results of TelelnterMed study. Cardiol J. 2014;21(5):539-546. doi:10.5603/CJ.a2014.0005

28. Ładyżyński $P$, Wójcicki JM. Home telecare during intensive insulin treatment - Metabolic control does not improve as much as expected. J Telemed Telecare. 2007;13(1):44-47. doi:10.1258/135763307779701167

29. Wojcicki JM, Ladyzynski P, Foltynski P. What we can really expect from telemedicine in intensive diabetes treatment: 10 years later. Diabetes Technol Ther. 2013;15(3):260-268. doi:10.1089/dia.2012.0242

30. Szymas J, Papierz W, Danilewicz M. Real-time teleneuropathology for a second opinion of neurooncological cases. Folia Neuropathol. 2000;38(1):43-46.

31. Szymas J, Wolf G, Papierz W, Jarosz B, Weinstein RS. Online Internet-based robotic telepathology in the diagnosis of neuro-oncology cases: A teleneuropathology feasibility study. Human pathology. 2001;32(12):1304-1308. doi:10.1053/hupa.2001.29647

32. Slodkowska J, Pankowski J, Siemiatkowska K, Chyczewski L. Use of the virtual slide and the dynamic real-time telepathology systems for a consultation and the frozen section intra-operative diagnosis in thoracic/pulmonary pathology. Folia Histochem Cytobiol. 2009;47(4):679-684. doi:10.2478/v10042-010-0009-z

33. Wasowski A, Skarzynski PH, Lorens A, Obrycka A, Walkowiak A, Bruski L. Remote fitting of cochlear implant system. Cochlear Implants Int. 2010;11(Suppl 1):489-492. doi:10.1179/14670101 0X12671177318105

34. Pankowska A, Zgoda M, Skarzynski H, Wasowski A, Geremek A. Home rehabilitation clinic as a form of support for parents of implanted children. Cochlear Implants Int. 2010;11(Suppl 1):360-363. doi:10.117 9/146701010X12671177989912 
35. Kamińska-Winciorek G. Telederm.org - Consolidation, diagnostic and consultative platform for doctors. Nowotwory. 2013;63:180-182.

36. Koziarska D, Wunsch E, Milkiewicz M, Wojcicki M, Nowacki P, Milkiewicz P. Mini-Mental State Examination in patients with hepatic encephalopathy and liver cirrhosis: A prospective, quantified electroencephalography study. BMC Gastroenterol. 2013;13:107. doi: 10.1186/1471-230X-13-107

37. Krzystanek M, Krupka-Matuszczyk I. Telepsychiatry - Psychiatric advice on the Internet. Psychiat Pol. 2003;37(6):1073-1082.

38. Krzystanek E, Opala G. Teleneurology: A new form of physicianpatient communication. Wiad Lek. 2005;58(1-2):21-24.

39. Lesnicka A. Polish e-therapy: A survey among specialists conducting psychotherapy via internet. Psychiatria. 2009;6:43-50.

40. Mierzynska A, Kowalska M, Stepnowska M, Piotrowicz R. Psychological support for patients following myocardial infarction. Cardiol J. 2010;17(3):319-324.

41. Glowacki M, Czernicki Z, Jurkiewicz J, Walasek N. Teleradiology in neurosurgery, based on the experience of the Department of Neurosurgery, Polish Academy of Sciences. Pol J Radiol. 2005;70:27-34.

42. Duplaga M, Soja J, Cala J, et al. The impact of teleconsultations at a referential centre on the management of pulmonary patients. Stud Health Technol Inform. 2004;105:92-99.

43. Walecki P, Sarapata K, Lason W, Pyrczak W, Roterman-Konieczna I, Balwierz W. Telemedical database of Hodgkin's disease. Stud Health Technol Inform. 2004;105:51-57.

44. Glinkowski W. Web-based support for fracture healing evaluation and monitoring. Telemed J E Health. 2011;17(3):201-210. doi:10.1089/ tmj.2010.0131

45. Glinkowski W, Michonski J, Glinkowska B, Zukowska A, Sitnik R, Gorecki A. Telediagnostic 3D school screening of back curvatures and posture using structured light method: Pilot study. Stud Health Technol Inform. 2012;176:291-294.

46. Glinkowski W, Michonski J, Zukowska A, Glinkowska B, Sitnik R, Gorecki A. The time effectiveness of three-dimensional telediagnostic postural screening of back curvatures and scoliosis. Telemed J E Health. 2014;20(1):11-17. doi:10.1089/tmj.2013.0107
47. Glinkowski W, Pawłowska K, Kozłowska L. Telehealth and telenursing perception and knowledge among university students of nursing in poland. Telemed J E Health. 2013;19(7):523-529. doi:10.1089/ tmj.2012.0217

48. Bujnowska-Fedak MM, Mastalerz-Migas A. Usage of medical internet and e-health services by the elderly. Adv Exp Med Biol. 2015;834:7580. doi:10.1007/5584_2014_74

49. Borkowski W, Mielniczuk H. New trends in child cancer information systems development in Poland. Med Wieku Rozwoj. 2003;7(3): 305-313.

50. Karlinska M, Rudowski R. E-Health in Polish local hospitals: Present state, requirements and possibilities. https://www.medetel.eu/ download/2007/Med-e-Tel_2007_Proceedings_book.pdf. Accessed April 7, 2017.

51. Kononowicz AA, Krawczyk P, Cebula G, et al. Effects of introducing a voluntary virtual patient module to a basic life support with an automated external defibrillator course: A randomised trial. BMC Med Educ. 2012;12:41. doi:10.1186/1472-6920-12-41

52. Szkolnicka B, Mitrus M, Morawska J, Satora L, Targosz D. Toxic exposure of children in 2004 - Telephone service of toxicology. Przegl Lek. 2005;62(6):564-567.

53. Duplaga M, Juszkiewicz K, Leszczuk M. Telelearning standards and their application in medical education. Stud Health Technol Inform. 2004;105:308-316.

54. Kosiedowski M, Mazurek C, Stroinski M, Weglarz J. Grid-supported Medical Digital Library. Stud Health Technol Inform. 2007;126:127-136.

55. Klar R, Pelikan E. Telemedicine in Germany: Status, chances and limits. Bundesgesundheitsblatt, Gesundheitsforschung, Gesundheitsschutz. 2009;52(3):263-269. doi:10.1007/s00103-009-0787-7

56. Brauns HJ, Loos W. Telemedicine in Germany: Status, barriers, perspectives. Bundesgesundheitsblatt, Gesundheitsforschung, Gesundheitsschutz. 2015;58(10):1068-1073. doi:10.1007/s00103-015-2223-5

57. Wang Z, Gu H. A review of telemedicine in China. J Telemed Telecare. 2009;15(1):23-27. doi:10.1258/jtt.2008.080508 